\title{
Posterior Soft Tissue Repair After Primary THA is Durable at Mid-term Followup: A Prospective MRI Study
}

\author{
Alexander S. McLawhorn MD, MBA $₫$, Hollis G. Potter MD, Michael B. Cross MD, \\ Friedrich Boettner MD, Weiyang Lim MBBS, FRCR, MMED, Yuo-yu Lee MS, \\ Paul M. Pellicci MD
}

Received: 23 November 2014/ Accepted: 28 May 2015/Published online: 6 June 2015

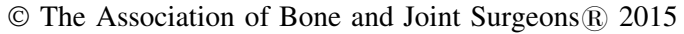

\begin{abstract}
Background The enhanced posterior soft tissue repair has reduced the frequency of dislocation after primary THA performed through the posterolateral approach. However, the long-term integrity of the repair is unknown and could influence surgeon choice regarding surgical technique and THA approach.

Questions/Purposes We asked: (1) What is the durability of the enhanced posterior soft tissue repair at a minimum of

The institution of one author (HGP) has received, during the study period, funding from General Electric Healthcare (Milwaukee, WI, USA).

One of the authors certifies that he (PMP), or a member of his or her immediate family, has or may receive payments or benefits, during the study period, an amount of USD 10,000-USD 100,000 from Smith \& Nephew, Inc (Memphis, TN, USA).

One of the authors certifies that he (FB), or a member of his or her immediate family, has or may receive payments or benefits, during the study period, an amount of USD 10,000-USD 100,000 from Smith \& Nephew, Inc (Memphis, TN, USA), an amount of less than USD 10,000 from DJ Orthopedics, LLC (Vista, CA, USA), and an amount of USD 100,001-USD 1,000,000 from Ortho Development Corp (Draper, UT, USA).

All ICMJE Conflict of Interest Forms for authors and Clinical Orthopaedics and Related Research ${ }^{\circledR}$ editors and board members are on file with the publication and can be viewed on request.

Each author certifies that his or her institution approved the human protocol for this investigation, that all investigations were conducted in conformity with ethical principles of research, and that informed consent for participation in the study was obtained.
\end{abstract}

A. S. McLawhorn ( $₫)$, M. B. Cross, F. Boettner, P. M. Pellicci Orthopedic Surgery, Hospital for Special Surgery, 535 East 70th Street, New York, NY 10021, USA

e-mail: mclawhorna@hss.edu

H. G. Potter, W. Lim

Radiology \& Imaging, Hospital for Special Surgery, New York, NY, USA
49 months using MRI to evaluate soft tissue to bone integrity? (2) How does the appearance of the posterior soft tissues change during this time? (3) Are there patient characteristics associated with the long-term imaging appearance of the posterior repair?

Methods All patients without a contraindication for MRI who were undergoing unilateral primary uncemented THA through a posterior approach between February and May 2005 were eligible for inclusion. Ninety percent consented to participate (36 of 40 patients), and 30 patients were followed prospectively with MRI postoperatively and again at 3 months; of those, 22 (73\%; 12 men, 10 women) completed the study by having another MRI study at a minimum of 49 months (mean, 51 months; range, 4959 months). Each patient underwent metal-artifact-reduction sequence MRI to evaluate the integrity of the posterior soft tissues, which had been repaired anatomically during primary THA at a minimum of 4 years earlier. The results were compared with those of prior MR images obtained immediately after surgery and at 3 months postoperatively. All patients were given a self-reported modified Harris hip score at the time of the most recent MRI study (maximum score $=81$ ).

Results At latest followup, 21 of $22(96 \%)$ patients had a posterior capsule in contact with bone, and 21 of $22(96 \%)$ had an intact quadratus femoris. Twenty-one patients (96\%) had soft tissue or a scar from the piriformis and

Y. Lee

Epidemiology and Biostatistics, Hospital for Special Surgery, New York, NY, USA 
conjoined tendons in continuity with bone. In these cases, the interface between the piriformis and conjoined tendons and the greater trochanter observed immediately postoperatively and at 3 months postoperatively became filled with hypointense tissue, with signal characteristics similar to tendon. Time from surgery was most associated with changes in native tendon-to-bone distances $(p<0.001)$ and MRI signal intensity of the repair $(\mathrm{p}<0.001)$.

Conclusions At followup of just more than 4 years, the posterior capsule and quadratus femoris most often were healed to bone. In the majority of patients, scar tissue between the piriformis and conjoined tendons and bone matured to achieve orientation and signal intensity resembling native tendon. We believe the enhanced posterior soft tissue repair facilitates this process. Our results provide a plausible explanation for improved postoperative stability observed in patients receiving an enhanced soft tissue repair compared with those in whom a repair is not performed.

Level of Evidence Level IV, therapeutic study.

\section{Introduction}

Historically, the posterior approach without soft tissue repair was associated with a higher risk of postoperative instability than alternative approaches for primary THA [10]. If the posterior soft tissues are repaired, the frequency of dislocation after a posterior approach is comparable to other techniques [1, 2, 10, 11]. Despite improved clinical results observed with the posterior soft tissue repair, skepticism remains regarding its long-term integrity $[9,16$, 17]. Pellicci et al. [12] reported that while the quadratus femoris and posterior capsule remained intact in more than 90\% (27 of 30) of patients at 3 months postoperatively, deficiencies in the native tendon-to-bone attachment occurred in $43 \%$ (13 of 30 ) of piriformis and 57\% (17 of 30 ) of conjoined tendon repairs.

In published models exploring tendon-to-bone repair, deficient tendon-bone interfaces initially are filled in with fibrovascular tissue, followed by tissue remodeling, and eventual formation of scar in continuity between tendon and bone $[3,5,15]$. For a THA through the posterior approach, when deficiencies are present between repaired tendon and bone, MR images show that the interval between them becomes filled with hyperintense, disorganized scar tissue at 3 months [12]. Muscle atrophy at this time suggests that the repair of the short external rotator tendons may not be functional [12]. However, the longitudinal appearance of intact and deficient posterior repairs has not been studied, to our knowledge, and may further indicate the anatomic substrates for improved THA stability observed with a repair of the posterior soft tissues. A greater understanding of the soft tissue response to the posterior approach may influence surgeons' choice regarding repair technique and the approach used for the THA.

The aim of this followup study was to determine the long-term appearance of the posterior soft tissue repair for THA. We asked: (1) What is the durability of the enhanced posterior soft tissue repair at minimum of 49 months using MRI to evaluate soft tissue to bone integrity? (2) How does the appearance of the posterior soft tissues change during this time? (3) Are there patient characteristics associated with the long-term imaging appearance of the posterior repair?

\section{Patients and Methods}

The institutional review board approved our prospective, descriptive cohort study. This followup investigation was performed at our institution from May 2009 through March 2010.

Patients who underwent primary uncemented THA by the senior surgeon (PMP) of the study, and who had MRI immediately postoperative and at 3 months postoperatively as part of the earlier study [12] were eligible for inclusion. For the original cohort, all patients without a contraindication for MRI undergoing unilateral primary uncemented THA through a posterior approach by the senior surgeon (PMP) between February and May 2005 were eligible for inclusion (80 patients). Forty patients were approached for enrollment, 36 patients $(90 \%)$ consented to participate, and 30 patients completed immediate postoperative and 3month MRI studies. For the current study, patients who were unavailable or unwilling to participate, patients who no longer were able to undergo MRI, and those receiving interval ipsilateral hip surgery were excluded. Thirty patients met inclusion criteria and 22 patients $(73 \%)$ were available for followup imaging (Table 1). Reasons for exclusion were interval placement of a pacemaker (one patient), lost to followup (three patients), refused participation (one patient), and unable to travel (three patients). None of the 30 patients experienced a postoperative dislocation or revision THA.

Index surgeries were performed as previously described [12]. Similar implants were used for all patients: Synergy $^{\mathrm{TM}}$ stem, Reflection ${ }^{\mathrm{TM}}$ shell with $0^{\circ}$ crosslinked polyethylene insert and 28-mm Oxinium ${ }^{\mathrm{TM}}$ femoral head (Smith \& Nephew, Inc, Memphis, TN, USA). The piriformis and conjoined tendons and the posterior capsule were repaired in separate layers using a transosseous technique and Number 2 Ethibond sutures (Ethicon Endo Surgery, Inc, Blue Ash, OH, USA) [1, 11, 12]. The entire 
Table 1. Study patient demographics

\begin{tabular}{lll}
\hline Variable & Mean & SD \\
\hline Height $(\mathrm{m})$ & 1.7 & 0.1 \\
Weight $(\mathrm{kg})$ & 79 & 18 \\
BMI $\left(\mathrm{kg} / \mathrm{m}^{2}\right)$ & 26 & 5 \\
Age at surgery (years) & 63 & 9 \\
\hline & Number & $\%$ \\
\hline Primary diagnosis & & \\
Dysplasia & 3 & 14 \\
Legg-Calvé-Perthes disease & 1 & 4 \\
Osteoarthritis & 18 & 82 \\
Smoker & & \\
Yes & 1 & 5 \\
No & 21 & 95 \\
Sex & & 45 \\
Women & 10 & 55 \\
Men & 12 & \\
\hline
\end{tabular}

quadratus femoris was taken down during the approach and then repaired anatomically with its overlying fibrofatty fascial layer using Number 0 Vicryl $^{\circledR}$ sutures (Ethicon Endo Surgery, Inc) [1, 11, 12].

All patients received the same aftercare [12]. They were mobilized without weightbearing restrictions on the first postoperative day and instructed to avoid hip flexion greater than $90^{\circ}$ and any internal rotation for 6 weeks after surgery.

Patients who were enrolled in the earlier study had their initial postoperative MRI performed at $3.4 \pm 0.6$ days after surgery (range, 2-4 days) and a followup MRI study performed $104.8 \pm 10.1$ days postoperatively (range, 91132 days). Prospectively, each patient in our study underwent MRI using the same metal-artifact-reduction sequence $[12,13]$. A senior board-certified musculoskeletal radiologist (HGP) interpreted all studies. Integrity of the soft tissue repair was measured and graded as previously detailed [12]. Atrophy of the short external rotator (obturator internus, superior gemellus, and inferior gemellus), piriformis, and quadratus femoris muscles were graded according to the classification of Goutallier et al. [7]. To keep reporting consistent with our previous study [12], Goutallier Grade 0 (no fat infiltration) corresponded to no atrophy, Grade 1 (fat streaking) corresponded to mild atrophy, Grade 2 (more muscle than fat) and Grade 3 (equal fat and muscle) were considered moderate atrophy, and Grade 4 (more fat than muscle) corresponded to severe atrophy. Patients also were given a self-reported modified Harris hip score at latest followup (maximum possible score $=81$ ) [8].

Signal intensity was measured using an $\mathrm{AW}^{\mathrm{TM}}$ Workstation (General Electric Healthcare, Milwaukee, WI, USA) for two $10-\mathrm{mm}^{2}$ ovoid regions of interest centered at the mid-portion of the repaired short external rotator tendons and over cortical bone of the ilium. The same repair segment was measured at different times, taking into account small variations in scan planes, and each intensity value was normalized to that of cortical bone.

Patient baseline demographics, clinical characteristics, and MRI appearance of soft tissue repairs were summarized with descriptive statistics. Inferential statistics were used to examine changes in soft tissue repairs immediately after surgery, 3 months postoperatively, and at last followup. Continuous variables were compared using repeated measures ANOVA. Comparisons of categorical variables were performed using Pearson chi-square or Fisher's exact test, as appropriate. The Cochran-Armitage test of trend was used to determine the significance of the changes with time.

Repeated measures multiple regression using the generalized estimating equations approach was used to identify patient characteristics associated with signal intensity and repair status, measured as distance from the piriformis and conjoined tendons to bone, controlling for time effect. Patient characteristics evaluated included age at surgery, sex, and BMI. Spearman correlation coefficient $(\rho)$ was used to explore the association between repair status measured at last followup and the Harris hip score.

All tests were two-sided with a significance level of 0.05 . Analyses were conducted using $\mathrm{SAS}^{\circledR}$ for Windows 9.3 (SAS Institute Inc, Cary, NC, USA).

\section{Results}

Durability of the Posterior Repair

At latest followup, the posterior capsule was in continuity with bone in 21 of 22 patients $(96 \%)$, with $18 \%(\mathrm{n}=4)$ being partially intact (Table 2 ). When partially intact, initial dehiscence occurred at the superior margin of the repair before 3 months postoperatively. At final followup, no native piriformis or conjoined tendon was in direct contact with bone. Twenty-one of $22(96 \%)$ patients had an intact quadratus femoris at final followup.

\section{MRI Changes of the Repair With Time}

There were no late or progressive failures of the posterior capsular repair. One patient had complete discontinuity between the posterior capsule and bone at 3 months that appeared partially intact at last followup, and one patient had a partially intact posterior capsule at 3 months that appeared intact at last followup. The mean tendon-to-bone distance for the piriformis increased from $6.5 \mathrm{~mm} \pm 4.3$ $\mathrm{mm}$ to $37 \mathrm{~mm} \pm 14 \mathrm{~mm}(\mathrm{p}<0.001)$ (Table 3$)$. Worsening 
Table 2. Summary of posterior soft tissue categorical variables

\begin{tabular}{|c|c|c|c|c|c|c|c|c|}
\hline \multirow[t]{2}{*}{ Variable } & \multicolumn{2}{|c|}{2 to 4 days postoperative } & \multicolumn{2}{|c|}{3 months postoperative } & \multicolumn{2}{|c|}{ Last followup } & \multirow[b]{2}{*}{$\mathrm{p}$ value } & \multirow[t]{2}{*}{$\mathrm{p}$ value for trends } \\
\hline & Number & $\%$ & Number & $\%$ & Number & $\%$ & & \\
\hline Piriformis repair & & & & & & & $<0.001$ & $<0.001$ \\
\hline Intact & 21 & 96 & 2 & 9 & 0 & 0 & & \\
\hline Not intact & 1 & 5 & 20 & 91 & 22 & 100 & & \\
\hline Piriformis atrophy* & & & & & & & $<0.001$ & $<0.001$ \\
\hline None & 15 & 68 & 5 & 23 & 0 & 0 & & \\
\hline Mild & 6 & 27 & 9 & 41 & 8 & 36 & & \\
\hline Moderate & 1 & 5 & 8 & 36 & 10 & 45 & & \\
\hline Severe & 0 & 0 & 0 & 0 & 4 & 18 & & \\
\hline Conjoined tendon repair & & & & & & & $<0.001$ & $<0.001$ \\
\hline Intact & 20 & 91 & 1 & 5 & 0 & 0 & & \\
\hline Not intact & 2 & 9 & 21 & 96 & 22 & 100 & & \\
\hline Short external rotator atrophy* & & & & & & & $<0.001$ & $<0.001$ \\
\hline None & 18 & 82 & 5 & 23 & 1 & 5 & & \\
\hline Mild & 4 & 18 & 8 & 36 & 5 & 23 & & \\
\hline Moderate & 0 & 0 & 9 & 41 & 10 & 46 & & \\
\hline Severe & 0 & 0 & 0 & 0 & 6 & 27 & & \\
\hline Quadratus femoris repair & & & & & & & 0.767 & NA \\
\hline Intact & 22 & 100 & 20 & 91 & 21 & 96 & & \\
\hline Partially intact & 0 & 0 & 1 & 5 & 1 & 5 & & \\
\hline Not intact & 0 & 0 & 1 & 5 & 0 & 0 & & \\
\hline Quadratus femoris atrophy* & & & & & & & 1.000 & NA \\
\hline None & 16 & 73 & 16 & 73 & 16 & 73 & & \\
\hline Mild & 4 & 18 & 4 & 18 & 4 & 18 & & \\
\hline Moderate & 0 & 0 & 0 & 0 & 0 & 0 & & \\
\hline Severe & 2 & 9 & 2 & 9 & 2 & 9 & & \\
\hline Posterior capsule repair & & & & & & & 0.298 & NA \\
\hline Intact & 21 & 96 & 16 & 73 & 17 & 77 & & \\
\hline Partially intact & 1 & 5 & 4 & 18 & 4 & 18 & & \\
\hline Not intact & 0 & 0 & 2 & 9 & 1 & 5 & & \\
\hline
\end{tabular}

Short external rotators = obturator internus, superior and inferior gemelli muscles; *modified classification of Goutallier et al. [7]: Grade $0=$ None; Grade 1 = Mild; Grade 2 or Grade 3 = Moderate; Grade $4=$ Severe; NA $=$ not applicable.

Table 3. Summary of posterior soft tissue continuous variables

\begin{tabular}{|c|c|c|c|c|c|c|c|}
\hline \multirow[t]{2}{*}{ Parameter } & \multicolumn{2}{|c|}{$\begin{array}{l}2 \text { to } 4 \text { days } \\
\text { postoperative }\end{array}$} & \multicolumn{2}{|c|}{$\begin{array}{l}3 \text { months } \\
\text { postoperative }\end{array}$} & \multicolumn{2}{|c|}{ Last followup } & \multirow[t]{2}{*}{$\mathrm{p}$ value } \\
\hline & Mean & SD & Mean & SD & Mean & SD & \\
\hline Piriformis to bone (mm) & 6.5 & 4.3 & 25 & 8 & 37 & 14 & $<0.001$ \\
\hline Conjoined tendon to bone (mm) & 7.4 & 6.3 & 27 & 7 & 35 & 10 & $<0.001$ \\
\hline Signal intensity* & 1.1 & 0.2 & 1.2 & 0.4 & 0.9 & 0.2 & $<0.001$ \\
\hline
\end{tabular}

* Signal intensity normalized to the signal intensity of cortical bone.

atrophy of the piriformis muscle was observed, with 15 patients $(68 \%)$ starting with no atrophy immediately postoperatively, to no patient without atrophy at last followup $(\mathrm{p}<0.001)$. Similarly, the conjoined tendon-to-bone distance increased from $7.4 \mathrm{~mm} \pm 6.3 \mathrm{~mm}$ to $35 \mathrm{~mm} \pm$ $10 \mathrm{~mm}(\mathrm{p}<0.001)$. Eighteen patients $(82 \%)$ had no short external rotator muscle atrophy initially, and only one (5\%) had no apparent atrophy at final followup $(\mathrm{p}<0.001)$. For 

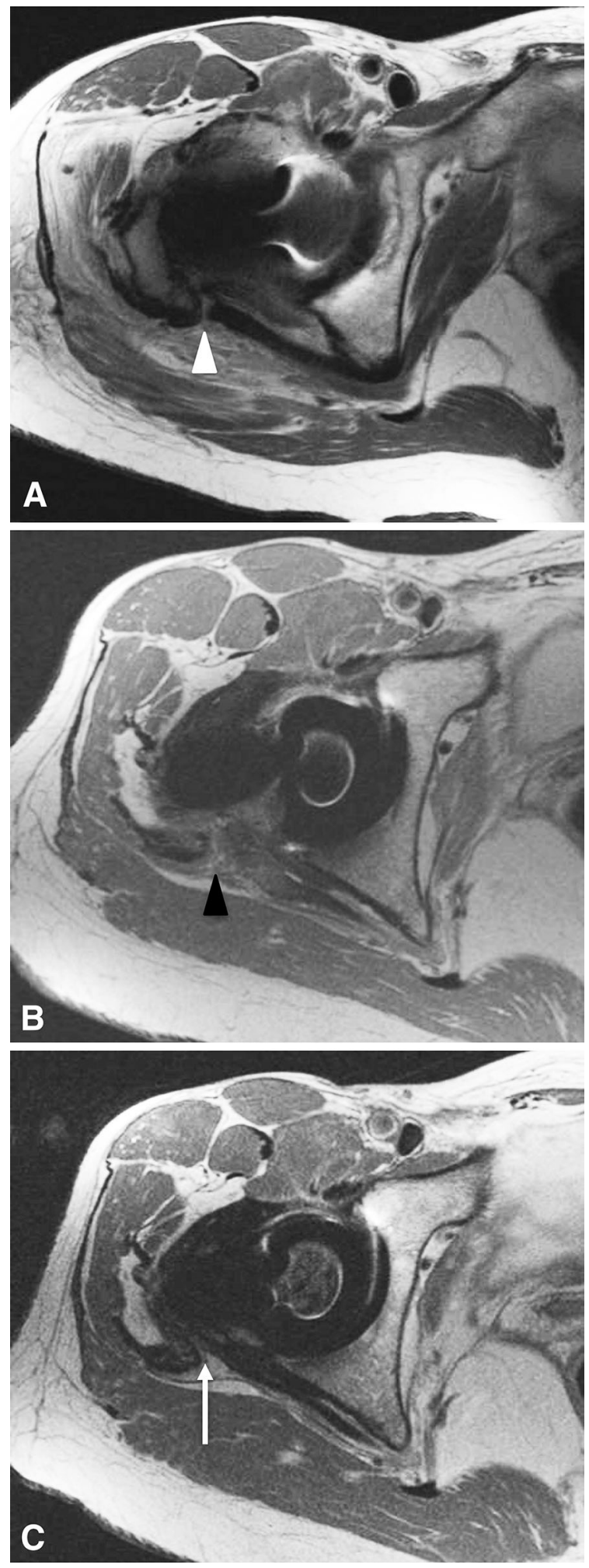

the quadratus femoris repair, there were no late failures. One patient with quadratus repair failure had heterotopic ossification develop in the area of dehiscence. Sixteen patients $(73 \%)$ had no atrophy, four (18\%) had mild
Fig. 1A-C Serial postoperative MR images from a representative study patient are shown. (A) An immediately postoperative axial MR image at the level of conjoined tendons shows anatomic approximation of the tendon to bone (white arrowheads). (B) An axial MR image at the level of the conjoined tendon repair 3 months after surgery shows interval gap formation between the tendon and bone, with interposed hyperintense tissue (black arrowhead). (C) An axial MR image obtained at the level of the conjoined tendon repair at final followup reveals low-intensity tissue in continuity with the conjoined tendon and bone (white arrow), representing a continuous layer of posterior pseudocapsule.

atrophy, and two (9\%) had severe atrophy initially, and the grading was unchanged at last followup $(\mathrm{p}=1.0)$.

Although bone-tendon deficiencies seen immediately postoperatively and at 3 months postoperatively increased in size, 21 of 22 patients (96\%) had a scar develop from the piriformis and conjoined tendons in continuity with bone (Fig. 1). Progressive maturation of the repair tissue was observed in all cases. This was characterized by increasing normalized signal intensity in the region of the repair from $1.1 \pm 0.2$ initially to $1.2 \pm 0.4$ at 3 months and decreasing signal intensity to $0.9 \pm 0.2$ at last followup ( $<<0.001$ ). At final followup, repair tissue signal and orientation were qualitatively similar to those of native tendon.

\section{Patient Factors Associated with Intact Repairs}

Increased time from surgery and older age were independently associated with increased distance between the piriformis tendon and bone (Table 4). Comparing the MR images from the last followup with the initial postoperative MR images, the effect size for time was $30 \mathrm{~mm}(95 \% \mathrm{CI}$, 24-37 mm; $p<0.001)$, and the effect size for age was $0.2 \mathrm{~mm}$ (95\% CI, 0.0-0.5 mm; $\mathrm{p}=0.035$ ). Increased time from surgery (initial MRI versus final MRI study) was independently associated with increased distance between the conjoined tendon and bone $(27 \mathrm{~mm}$; 95\% CI, $23-$ $31 \mathrm{~mm} ; \mathrm{p}<0.001)$ and decreasing signal intensity $(-0.26$; $95 \% \mathrm{CI},-0.39$ to $-0.14 ; \mathrm{p}<0.001)$. Spearman coefficients exploring the nonparametric relationship between modified Harris hip score at last followup and periprosthetic soft tissues features (ie, tendon-to-bone distances, signal intensities, and muscle atrophy) were between -0.1 and 0.3 and all $\mathrm{p}$ values exceeded 0.1 .

\section{Discussion}

The enhanced posterior soft tissue repair after THA via the posterior approach adheres to modern surgical principles, emphasizing meticulous soft tissue handling, restoring native soft tissue planes, and eliminating dead space [11]. The repair reduces the risk of postoperative THA 
Table 4. Summary of regression analyses for posterior soft tissue continuous variables

\begin{tabular}{|c|c|c|c|c|c|c|c|c|c|c|c|c|}
\hline \multirow[t]{2}{*}{ Factor } & \multicolumn{4}{|c|}{ Piriformis to bone (mm) } & \multicolumn{4}{|c|}{ Conjoined tendon to bone (mm) } & \multicolumn{4}{|c|}{ Signal intensity } \\
\hline & $\begin{array}{l}\text { Effect size } \\
(\mathrm{mm})\end{array}$ & $95 \% \mathrm{C}$ & & $\mathrm{p}$ value & $\begin{array}{l}\text { Effect size } \\
(\mathrm{mm})\end{array}$ & $95 \% \mathrm{C}$ & & $\mathrm{p}$ value & $\begin{array}{l}\text { Effect size } \\
(\mathrm{mm})\end{array}$ & $95 \% \mathrm{CI}$ & & $\mathrm{p}$ value \\
\hline Intercept & -3.8 & -21 & 13 & 0.658 & 30 & -2.6 & 63 & 0.0713 & 0.81 & -0.13 & 1.74 & 0.09 \\
\hline Time 2 vs 1 & 18 & 15 & 22 & $<0.001$ & 20 & 16 & 23 & $<0.001$ & 0.03 & -0.15 & 0.21 & 0.73 \\
\hline Time 3 vs 1 & 30 & 24 & 37 & $<0.001$ & 27 & 23 & 31 & $<0.001$ & -0.26 & -0.39 & -0.14 & $<0.001$ \\
\hline BMI & -0.2 & -0.5 & 0.2 & 0.361 & -0.3 & -0.8 & 0.2 & 0.188 & 0.01 & 0.00 & 0.03 & 0.071 \\
\hline Age & 0.2 & 0.0 & 0.5 & 0.035 & -0.2 & -0.6 & 0.2 & 0.318 & 0.00 & -0.01 & 0.01 & 0.596 \\
\hline Male vs female & -1.6 & -5.7 & 2.5 & 0.433 & -1.2 & -5.9 & 3.6 & 0.636 & 0.10 & 0.00 & 0.21 & 0.054 \\
\hline
\end{tabular}

dislocation [10, 11]. Despite this observation, skepticism remains regarding the long-term integrity of the repair of the piriformis and short external rotator tendons and the posterior capsule $[9,16,17]$. Previous investigators $[9,16-$ 18], and Pellicci et al. [12], have reported disparate shortterm ( $\leq 3$ months) imaging results of the posterior repair using plain radiographic [9, 16, 17], ultrasound [18], and MRI techniques [12]. In the study by Pellicci et al. [12], measurable deficiencies existed between repaired tendons and bone in approximately $1 / 2$ of the patients, and the longterm potential for remodeling of the posterior pseudocapsule was uncertain. The longer-term integrity of the repair has not been reported previously and patient-specific factors have not been correlated to healing or failure, to our knowledge. Therefore, we used prospectively collected metal-artifact-reduction sequence MRI studies over time to determine the durability of the enhanced posterior soft tissue repair at 4 years after THA to explore changes to the posterior soft tissues during this interval and to identify patient characteristics associated with the MRI appearance of the posterior repair.

Our study has some limitations. First, only $73 \%$ of patients were available for followup, and the study was performed on a small number of patients, restricted by the original cohort size. However, to our knowledge no patient experienced a dislocation or revision THA. Only one patient refused participation in this followup study, and we do not believe that patients who followed up were materially different from those who did not. Second, observed relationships from regression analyses are limited by the sample size, which influenced the stability of the regression models. Therefore, reliable results could be obtained only for basic characteristics: time from surgery, age, BMI, and sex. A larger study would be necessary to explore associations between the appearance of the repair and preoperative diagnoses or medical comorbidities. Third, most patients had a good Harris hip score and no patient experienced a postoperative dislocation; therefore, assessment of correlation between imaging and functional outcome was limited by a ceiling effect observed for the modified Harris hip score, and we could not correlate integrity of the repair to risk for THA instability. Fourth, although metal-artifact-reduction sequence MRI protocols provide extraordinary detail of the periprosthetic soft tissues [12, 13], signal intensity is not correlated to any specific material property of tendon. Rather, it provides a quantitative comparison of the repair tissue. Measurement of $\mathrm{T} 2 *$ relaxation properties would provide a more definitive assessment of tendon and tissue collagen orientation, but requires specialized software to maintain the tissue dynamic range of Type 1 collagen. Finally, implant alignment is an important factor contributing to THA stability. Although acetabular and femoral orientations may have helped limit dislocations in this series, they were not measured and likely had limited influence on the appearance of the posterior soft tissues.

Past studies have concluded that a posterior repair fails during the early postoperative period based on indirect assessment on plain radiographs [9, 16, 17]. Prior ultrasound [18] and MRI [12,14] studies have reported more positive results. All studies have been limited by short-term followup. At minimum followup of more than 49 months we observed that $96 \%$ of quadratus femoris and posterior capsule repairs were intact, and while tendon-to-bone distances increased with time, the piriformis and short external rotator muscles progressively atrophied and hypointense scar created continuity between tendon stumps and bone in $96 \%$ of patients. Quantified changes in signal intensity paralleled maturation of the scar tissue, from hyperintense tissue at 3 months postoperatively to hypointense tissue at final followup. Time from surgery was most strongly associated with piriformis and short external rotator tendon-to-bone distances. To a lesser extent, older age was correlated with increased piriformis tendon-bone distance, similar to observations reported in other tendon-to-bone healing studies [4, 19].

We propose that our results correspond to those of other models for soft tissue healing to bone, such as those reported for rotator cuff repair $[6,15]$. Typically, there is failure of the primary repair, creating a discontinuity 
between bone and soft tissue. Continuity between the native tissue stump and bone occurs through reactive scar formation and not through regeneration of a histologically normal soft tissue to bone interface $[6,15]$. The posterior repair may serve as a scaffold for scar between short external rotator tendons and the greater trochanter and eventual maturation of the posterior pseudocapsule. Delayed formation of an organized pseudocapsule and the inability to resolve visually individual elements of the repair, per other studies [9, 16, 17], may partially explain the dichotomous findings between radiographic studies [9, $16,17]$ reporting high failure rates of the repair and clinical studies $[10,11]$ reporting significant reduction in the incidence of postoperative instability in patients with a posterior soft tissue repair.

Progressive muscle atrophy was observed for the piriformis and short external rotator muscles, supporting the prior supposition that the posterior capsule and tendon repairs serve principally as static restraints to posterior THA instability [12]. Although the contribution of the quadratus femoris to THA stability is unknown, it healed in the majority of patients in the current study and did not atrophy. When the quadratus femoris is not repaired, it heals in only $44 \%$ of patients [18].

If an enhanced posterior soft tissue repair is performed during THA via the posterior approach, the majority of patients will retain an intact posterior capsule repair, and scar tissue between the short external rotator tendon stumps and bone eliminates posterior dead space and matures in such a way to achieve orientation and signal characteristics resembling native tendon. We believe that the soft tissue repair facilitates this process and an anatomic repair of the posterior soft tissues contributes to long-term THA stability. In our experience, restoration of native soft tissue planes also facilitates exposure during revision surgery, which might prove advantageous over nonanatomic repairs [2]. Further studies are necessary to quantify the individual contributions of the repair to THA stability and functional outcomes and to identify individual patient characteristics that may affect successful long-term repair. Comparative studies should elucidate the differential soft tissue response to THA performed through alternative approaches.

\section{References}

1. Bottner F, Pellicci PM. Review: posterior soft tissue repair in primary total hip arthroplasty. HSS J. 2006;2:7-11.
2. Browne JA, Pagnano MW. Surgical technique: a simple softtissue-only repair of the capsule and external rotators in posteriorapproach THA. Clin Orthop Relat Res. 2012;470:511-515.

3. Farshad M, Gerber C, Snedeker JG, Frauenfelder T, Meyer DC. Structure of retracted tendons after staged repair following continuous traction. Knee Surg Sports Traumatol Arthrosc. 2011;19:2131-2137.

4. Galatz LM, Silva MJ, Rothermich SY, Zaegel MA, Havlioglu N, Thomopoulos S. Nicotine delays tendon-to-bone healing in a rat shoulder model. J Bone Joint Surg Am. 2006;88:2027-2034.

5. Gerber C, Meyer DC, Frey E, von Rechenberg B, Hoppeler H, Frigg R, Jost B, Zumstein MA. Neer Award 2007: Reversion of structural muscle changes caused by chronic rotator cuff tears using continuous musculotendinous traction: an experimental study in sheep. J Shoulder Elbow Surg. 2009;18:163-171.

6. Gerber C, Schneeberger AG, Perren SM, Nyffeler RW. Experimental rotator cuff repair: a preliminary study. J Bone Joint Surg Am. 1999;81:1281-1290.

7. Goutallier D, Postel JM, Bernageau J, Lavau L, Voisin MC. Fatty muscle degeneration in cuff ruptures: pre- and postoperative evaluation by CT scan. Clin Orthop Relat Res. 1994;304:78-83.

8. Harris WH. Traumatic arthritis of the hip after dislocation and acetabular fractures: treatment by mold arthroplasty. An end-result study using a new method of result evaluation. J Bone Joint Surg Am. 1969;51:737-755.

9. Kao JT, Woolson ST. Piriformis tendon repair failure after total hip replacement. Orthop Rev. 1992;21:171-174.

10. Kwon MS, Kuskowski M, Mulhall KJ, Macaulay W, Brown TE, Saleh KJ. Does surgical approach affect total hip arthroplasty dislocation rates? Clin Orthop Relat Res. 2006;447:34-38.

11. Pellicci PM, Bostrom M, Poss R. Posterior approach to total hip replacement using enhanced posterior soft tissue repair. Clin Orthop Relat Res. 1998;355:224-228.

12. Pellicci PM, Potter HG, Foo LF, Boettner F. MRI shows biologic restoration of posterior soft tissue repairs after THA. Clin Orthop Relat Res. 2009;467:940-945.

13. Potter HG, Nestor BJ, Sofka CM, Ho ST, Peters LE, Salvati EA. Magnetic resonance imaging after total hip arthroplasty: evaluation of periprosthetic soft tissue. J Bone Joint Surg Am. 2004;86:1947-1954.

14. Ranawat CS, Meftah M, Potter HG, Ranawat AS. The posterior approach in THR: assuring capsular stability. Orthopedics. 2011;34:e452-455.

15. Rodeo SA, Potter HG, Kawamura S, Turner AS, Kim HJ, Atkinson BL. Biologic augmentation of rotator cuff tendonhealing with use of a mixture of osteoinductive growth factors. $J$ Bone Joint Surg Am. 2007;89:2485-2497.

16. Stähelin T, Drittenbass L, Hersche O, Miehlke W, Munzinger U. Failure of capsular enhanced short external rotator repair after total hip replacement. Clin Orthop Relat Res. 2004;420:199-204.

17. Stähelin T, Vienne $P$, Hersche $O$. Failure of reinserted short external rotator muscles after total hip arthroplasty. J Arthroplasty. 2002;17:604-607.

18. Su EP, Mahoney CR, Adler RS, Padgett DE, Pellicci PM. Integrity of repaired posterior structures after THA. Clin Orthop Relat Res. 2006;447:43-47.

19. Tashjian RZ, Hollins AM, Kim HM, Teefey SA, Middleton WD, Steger-May K, Galatz LM, Yamaguchi K. Factors affecting healing rates after arthroscopic double-row rotator cuff repair. Am J Sports Med. 2010;38:2435-2442. 